\title{
Perceptions of Writing Confidence, Critical Thinking, and Writing Competence among Registered Nurse-Learners Studying Online
}

\author{
Lorraine Carter, Laurentian University
}

\section{Abstract}

Historically, nursing education has recognized that writing enhances critical thinking, the basis of the clinical reasoning process. The online learning recently adopted by Nursing involves considerable writing, which may enhance critical thinking more than face-to-face courses. In the study reported here, the critical thinking and writing experiences of 34 registered nurses in an online course at an Ontario university were considered from several perspectives: perception of writing competence; demonstration of levels and kinds of critical thinking; and demonstration of writing competence. Although the participants' perceptions of their writing competence increased significantly, these results were not reflected in their levels of writing competence

\section{RÉSUMÉ}

Historiquement, les éducateurs en sciences infirmières reconnaissent que l'action d'écrire parfait la pensé critique ce qui est à la base du processus clinico-raisonnement. L'apprentissage en ligne récemment adopté en Sciences infirmières nécessite d'écrire énormément, ce qui pourrait parfaire la pensée critique plus que dans les cours à encadrement face à face. Dans cet article, cette étude considèrent de plusieurs perspectives les expériences de pensée critique et d'écrire de 34 infirmières autorisées suivant un cours en ligne offert par une université en Ontario : la perception de la compétence à l'écrit ; la démonstration de plusieurs niveaux ainsi que de plusieurs sortes de pensée critique; et la démonstration de la compétence à l'écrit. Bien que la perception 
when compared to that of younger nurse-learners and students in an Arts course at the university. The study did not demonstrate that online writing results in different levels of critical thinking; it did, however, suggest a connection between and among online writing, different kinds of critical thinking, and assignment design. envers la compétence à l'écrit des participantes se soit accrue significativement, ces mêmes résultats n'étaient pas exprimés dans leur niveau de compétence à l'écrit lorsque ces résultats étaient comparés à ceux des apprenantes-infirmières plus jeunes ainsi qu'à ceux des étudiants inscrits à la Faculté des Arts de l'université. Lorraine Carter ne démontre pas dans son étude que différents niveaux de pensée critique sont les résultats d'écrire en ligne ; par contre, cette étude suggère un lien entre et parmi l'écrire en ligne, les différents sortes de pensée critique, et la façon que sont conçus les devoirs.

\section{Introduction AND Purpose}

Over the last decade, the study of critical thinking and writing has become an important area of research in online education. Although understanding these variables and their connectedness is valuable in all subject areas, understanding their interplay in online nursing courses is especially important because critical thinking has long been recognized as foundational to the clinical-reasoning process that nurses use every day (Daroszewski, Kinser, \& Lloyd, 2004; Kennison \& Misselwitz, 2002; Kessler \& Lund, 2004; Smith \& Johnston, 2002). Additionally, in the majority of university-level online courses, including nursing courses, writing is a primary learning methodology (Anderson, 2003; Garrison \& Anderson, 2003).

The doctoral study that informs this article explored the writing perceptions, the levels of critical thinking demonstrated in their writing, and the writing experiences of a group of post-RNs taking an online course from Laurentian University in Sudbury, Ontario. The study assessed two hypotheses:

- online courses that include asynchronous reflective-writing activities increase learners' perception of their competence as a writer

- online courses that include asynchronous reflective-writing activities facilitate the demonstration of critical-thinking skills through writing. 
Because of challenges related to the second hypothesis, the study included post-hoc analyses related to the various kinds of critical thinking demonstrated in participants' writing and writing competence, as defined by a cross-section of grammatical markers.

\section{CONTEXT}

Increasing numbers of registered nurses in Ontario are seeking baccalaureatelevel education through online education, and this same trend is evident among nurses striving to meet their continuing professional development (CPD) goals. The reasons for this growth include the 2005 baccalaureate entry-to-practice requirement and the continuous learning required by those practicing in the constantly changing field of nursing.

In Spring 2000, when the baccalaureate-to-practice requirement was announced, only $20 \%$ of Ontario nurses held a baccalaureate degree-the remaining $80 \%$ held a nursing diploma (Council of Ontario Universities Highlights, 2000). Thus, in order to compete with their younger colleagues for positions of leadership and responsibility, many nurses who graduated before 2005 have had to pursue their degrees. Nurses' interest in continuing education activities is also motivated by the constantly changing healthcare field, as well as by incentives related to salary increases and promotion opportunities. All of these factors are leading unprecedented numbers of nurses to take additional courses, programs, certificates, and other forms of instruction.

Many registered nurses are aware of the educational opportunities available to them, but accessing continuing education can be a complex undertaking. Not surprisingly, then, online education-with its flexibility around time and place- has become popular with nurses. Although, historically, nurses have been seen as reluctant users of computers and other technologies (Gibson \& Rose, 1986), this situation began to change in the late 1990s, when computer-based applications became a part of daily nursing practice.

\section{TheOretical Framework}

The learning theory underpinning the study that informs this article is constructivism. The driving principle of constructivism is that knowledge is individually and/or socially constructed by learners based on their interpretations of experience. Knowledge is not transmitted; instead, it is created or constructed by the learner. As Seels noted, "Learning occurs because personal knowledge is constructed by an active and self regulated learner ... who reflects on theoretical explanations" (1989, p. 11). Reflecting 
on constructivism and online learning from a historical perspective, the contributions of Piaget, Vygotsky, and von Glaserfeld stand out.

Piaget, a developmental constructivist who introduced the term "constructivism" to psychology, focused on knowing rather than being. Over time, Piaget's theories were adopted by educational theorists and practitioners. Vygotsky is remembered for his contributions to social constructivism, the belief that culture and context shape understanding. He also favoured the concept of learning as a social construct enabled by language and discourse. In von Glaserfeld's world of radical constructivism, there is no indisputable world-no objective reality. As Jonassen (1991b) suggested, "There is no single entity or any objective entity that can be described in any objective way; rather, the real world is a product of the mind that constructs that world" (p. 9). Based on this understanding of the world and of learning, every person's understanding of the learning experience is equally valid.

Many educators regard the online classroom as a valuable venue for exploring constructivist assumptions (Ally, 2004). In the tradition of Piaget, cognitive exchange can be facilitated by learners who reside in different physical settings but explore ideas aggressively and energetically through the written word. Similarly, social interaction through online writing often leads to both the establishment of a persona for the learner and the consideration of multiple and contrary perspectives. In online courses that use threaded bulletin/discussion forums, rich reflection and abstraction can also occur, as the time taken to prepare a written response may result in more thoughtful observations than in a face-to-face situation. In online settings, teachers often assume different roles than in more traditional classrooms; some of these roles include mentor, coach, and challenger (Mujtaba \& Preziosi, 2006). Considering all of these ideas together, in online courses in which the written word is a primary learning strategy, knowledge tends to be constructed through discourse and interaction rather than through the transmission of information (Murphy \& Cifuentes, 2001).

The online course taken by the nurses in this research study was informed principally by constructivism. Titled "Nursing Healthy Individuals and Families," the course focused on the nursing process, group dynamics, teaching and learning, critical thinking and reflective practice, family assessment, growth and development, and therapeutic communication. In the practice component of the course, students visited a healthy family for assessment and teaching purposes. What the students learned through this visit informed their three written course assignments, as they shared knowledge and constructed meaning about the families. In the first assignment, students were asked to discuss the congruency between their intentions for the visit and what actually occurred. They were then required to reflect on their visit in relation to Johns' (1995) model of ways of knowing and to consider 
their experience in relation to perceptions, influencing factors, alternative perspectives, and praxis. In the second assignment, they were asked to apply an assessment model, or framework, to the family they had visited. For the third assignment, they were to construct a teaching session for the family. For each of these assignments, students were asked to dialogue with their fellow students and the teacher on the course website's bulletin board while they prepared their assignment.

Besides completing the family-based work, students were required to complete and share postings on reflective practice and critical thinking. In their reflective-practice postings, they were challenged to describe experiences, identify influencing factors, consider personal ways of responding to specific situations, describe personal learning, and identify the ways of knowing that were involved. In their critical-thinking postings, they demonstrated their process of critical thinking by answering questions based on a case study.

As well as the three written assignments, the course included learning strategies that are commonly regarded as transmissive and experiential in nature. The transmissive learning experiences included teacher-prepared notes and formal readings. Many of the learning activities accompanying the online lectures and readings were case based or experiential. Figure 1 is a pictorial representation of all of these elements and their relationships, which, taken together, represent the study's theoretical framework.

\section{Reflective Writing and Narrative Pedagogies in Nursing Education}

Nursing students are challenged "to reflect on their practice, explore reactions, discover relationships, and connect meanings to past experiences" (Kennison \& Misselwitz, 2002, p. 239), and reflective writing is one way in which nursing educators foster this kind of learning. According to Burrows (1995), reflective writing helps nurse-learners describe significant events, explore affective responses, and answer questions such as: What have I learned from this experience? How would I behave given a similar situation? In what ways do nursing and related theories explain the situation? Such personal dialogue may elicit candid self-evaluation, strategies for selfcorrection, and future actions. Written reflective exercises, with appropriate structuring and feedback, have also been reported to enhance critical thinking (Brown \& Sorrell, 1993; Ibarreta \& McLeod, 2004; Kennison \& Misselwitz, 2002; Sedlak, 1997).

Online education offers numerous ways for students to evolve into discipline-specific writers. An effective discipline-specific writer expresses ideas within a particular discourse community; in this study, that community 


$$
\begin{aligned}
& \text { EL }=\text { Experiential Learning } \\
& \mathrm{CL}=\text { Constructivist Learning } \\
& \mathrm{TL}=\text { Transmissive Learning } \\
& \mathrm{ID}=\text { Instructional Design }
\end{aligned}
$$

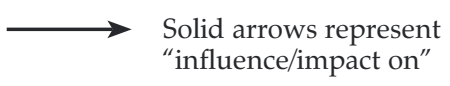

$\leftarrow-\rightarrow$ Broken arrows represent "borrowing components from"

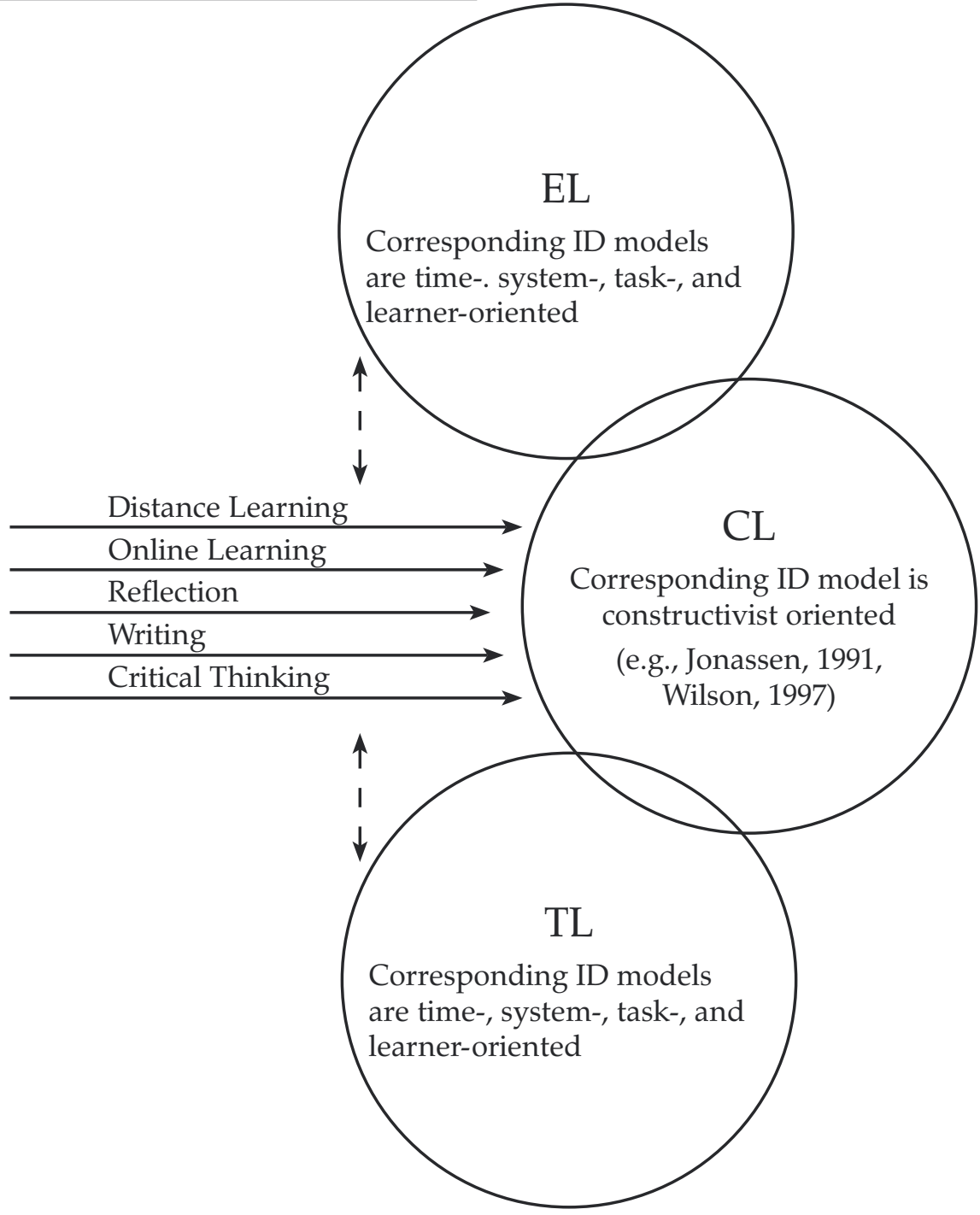

Figure 1: An inclusive constructivist theoretical framework coalescing from competing models and constructed variables. 
was the community of baccalaureate-prepared nurses. Generally speaking, discipline-specific writing involves critical-thinking patterns that are congruent with the area of study, as well as competence in using relevant writing conventions.

\section{Focus of the Study}

Based on the prevalence of online nursing courses in contemporary continuing education, the study examined whether online nursing courses with reflective-writing activities increased nurse-learners' perceptions of their writing competence and whether different levels of critical thinking were evident in their writing. Post-hoc analyses, carried out because of inter-rater reliability challenges regarding the level of critical thinking, examined these nurses' writing for evidence of different kinds of thinking and of writing competence as defined by pre-selected measures. This work enabled the participants' perceptions about writing in relation to their performance as writers to be considered.

\section{Study Methods}

The study had 84 participants: 34 post-RN working nurses, 28 undergraduate nursing students, and 22 undergraduate sociology students. The working nurses comprised the experimental group, while the undergraduate nursing students made up comparison group \#1 and the undergraduate sociology students comparison group \#2.

The 34 participants in the experimental group were registered nurses enrolled in a baccalaureate-level online course as part of a post-RN degree program in its fifth offering at Laurentian University in Sudbury, Ontario. Laurentian University is a mid-sized university that offers several healtheducation programs, including nursing, midwifery, social work, and medicine. Laurentian has a centralized unit for continuing and distance education called the Centre for Continuing Education.

The process of choosing comparison group \#1 presented several challenges. It was important to work with learners from the same university given the different orientations that universities have toward online courses, instructional design, and nursing education itself (Ko \& Rossen, 2004). Therefore, the director of Nursing at Laurentian was asked to identify an appropriate comparison group from nursing. As there were no other post-RN courses offered online during the time of the study, the director identified a face-to-face undergraduate nursing course in which students do a great deal of reflective writing. Although the groups did not match in terms of age and professional experience, it was anticipated that the study might yield findings about the writing experiences of two types of nurselearners enrolled in the same school. Because the differences between the 
two nursing groups were recognized as a confounding variable, adjustments were made to the study design: a pre and post design was used, with participants acting as their own control.

Comparison group \#2 consisted of students taking a term-length online course in the sociology of adolescence. According to the instructor, online writing was the primary means by which students reflected on the issues of adolescence and shared their perspectives. This course, like the one taken by the post-RN nurses, was designed by the Centre for Continuing Education, based on similar instructional-design principles. Students in these two courses also experienced comparable administrative support from the centre.

The participation rates for the two comparison groups were higher than for the experimental group. In comparison group \#1, $60 \%$ of the students agreed to participate, while $50 \%$ of comparison group \#2 participated; just $26 \%$ of the post-RN nurses took part. The significantly lower participation rate of the post-RN nurses may point to the situational uniqueness of postRN learners, such as busy professional lives and complex community and family responsibilities. Their lower participation rate may also be related to workplace stressors and the inability to participate in extra projects, such as research studies (McVicar, 2003; Stordeur, D'Hoore, \& Vandenberghe, 2001). Moreover, the higher participation of the first comparison group may have been due to the face-to-face visit made by the researcher to explain the study and recruit participants. The post-RN nurses in the experimental group and the sociology students in comparison group \#2 all received a letter through the regular mail asking them to participate in the study; yet, interestingly, there was a higher response rate from the younger sociology students. It is possible that the older nurses did not value the study in the same way as the younger students, even though, nurses are typically eager to support nursing-related initiatives whenever they can (S. Mossey, personal communication, September 2006).

Because of the number of students in the post-RN course $(n=130)$, the course was offered as three sections, each section with its own instructor. All instructors were highly experienced, mid-career female faculty members. Two were part-time instructors, while the third was a full-time faculty member. This course was the first distance-based teaching experience of any kind for the full-time faculty member. Of the two part-time instructors, one had taught two print-based distance courses (supported by teleconferences) and an Internet-based course, while the other had no experience teaching distance courses.

The instructors for the two comparison groups were also highly experienced female teachers. The instructor for comparison group \#2 had considerable experience in the development and delivery of distance-education courses, as well as online courses. 


\section{Study Design and Data Collection}

All participants, except those in the face-to-face nursing course, completed online questionnaires. Links to the surveys were provided via course website bulletin boards. The first survey was available during the first two weeks of the term, the second survey during the second last week of the term.

As noted earlier, the online students received a letter of information about the project and a consent form through the regular mail. They were asked to return their signed consent forms in the postage-paid envelope that was included in their information package. Ethics approval was procured through the respective Research Ethics Boards (REB) of Laurentian University and the University of Windsor. The researcher visited students in the face-to-face course in the first week of classes to invite participation, collect signed consent forms, and administer a hard copy of the online survey. A second visit was made in the second last week of classes to distribute the follow-up survey.

All writing samples were taken from assignments that students completed near the end of the term. These assignments were graded, in contrast with ungraded learning activities and/or written "homework."

\section{Data Analysis}

Based on the first survey, data pertaining to gender and age, education and employment, geographical communities, and prior experience with online education and online communication/writing tools (found in the Self-report Data Related to Online Education section) were collated. Participants' perceptions of their competence in four skill areas generally required in university-level online courses were analyzed via a three-way ANOVA, with Group, Scale, and Time as the independent variables.

Participants' writing samples were assessed for evidence of critical thinking, which was an identified focus in all three assignments. Each sample was scored by two different raters from Laurentian University. The scorers had similar backgrounds in the teaching and assessment of writing; each taught in the Department of English at Laurentian and had more than 20 years of teaching experience in writing. The scores generated were based on a four-point rubric called the Holistic Critical Thinking Scoring Rubric, where 4 is high and 1 is low (Facione \& Facione, 1992). A score of 4 means that the writer consistently meets all or almost all of the following criteria: accurately interprets evidence, statements, graphics, questions, etc.; identifies the salient arguments (reasons and claims) pro and con; thoughtfully analyzes and evaluates major alternative points of view; draws warranted, judicious, non-fallacious conclusions; justifies key results and procedures; explains assumptions and reasons; and follows where evidence and reasons 
lead. A score of 1 means that the writer consistently meets all or almost all of the following criteria: offers biased interpretations of evidence, statements, graphics, questions, information, or the points of view of others; fails to identify or hastily dismisses strong, relevant counter-arguments; ignores or superficially evaluates obvious alternative points of view; argues using fallacious or irrelevant reasons and unwarranted claims; neither justifies results or procedures nor explains reasons; maintains or defends views based on self-interest or preconceptions; and exhibits close-mindedness or hostility to reason (Facione, Facione \& Giancarlo, 2001, p. 8).

Other rubrics are available for assessing critical thinking, but this one was chosen for two reasons. First, this rubric is based on an understanding of critical thinking that corresponds to the critical thinking discussed by the instructors involved in the study. Second, both graders had had experience with a comparable four-point scoring grid based on their participation in the Writing across the Curriculum (WAC) program at Laurentian University.

As previously noted, this assessment activity was conducted by two independent raters, specifically, the researcher and a university instructor with similar credentials and educational experience teaching writing at Laurentian. The researcher spent one hour with the second rater in order to familiarize her with the rubric and the assignments. A correlation of the scores provided by the two raters was conducted to determine inter-rater reliability.

For all statistics across the study, an alpha level of 0.05 was selected for statistical significance.

\section{STUdy ResUlts}

The findings discussed here are based on demographic data, self-report data related to online education, self-perceptions of competence in skill areas required in university-level online courses, and writing competence.

\section{Demographic Data}

\section{Gender and Age}

The experimental group was exclusively female. The two comparison groups were also female, with the exception of one male in comparison group \#1. When age was configured in terms of two categories-20 to 35 years inclusive and 36 years plus - the experimental group had a larger portion of older students-there were almost twice as many older students in the experimental group. 


\section{Education and Employment}

In the experimental group, $4.5 \%$ of respondents indicated that Grade 12 was their highest educational level and 9.1\% reported it as Grade 13. These participants $(13.6 \%)$ were older nurses who had "trained" in hospital-training programs that existed before nursing was taught in community colleges and universities. All participants in the two comparison groups reported university education as their highest level of education.

Table 1 shows the participants' educational goals. Participants were free to choose as many as applied to them from six choices. Career advancement was the only goal that was different at a statistically significant level. This finding was expected and confirms that career goals differ according to age.

Table 1: Educational Goals as Identified by Participants

\begin{tabular}{|c|c|c|c|c|}
\hline Goal & $\begin{array}{c}\text { Experimental } \\
(n=34)\end{array}$ & $\begin{array}{c}\text { Comparison } \\
\# 1(n=28)\end{array}$ & $\begin{array}{c}\text { Comparison } \\
\# 2(n=22)\end{array}$ & $p$ \\
\hline University degree & $90.6 \%$ & $96.4 \%$ & $100.0 \%$ & .28 \\
\hline University credits & $9.4 \%$ & $21.4 \%$ & $28.6 \%$ & .19 \\
\hline $\begin{array}{l}\text { Continuing } \\
\text { education }\end{array}$ & $59.4 \%$ & $32.1 \%$ & $33.3 \%$ & .06 \\
\hline $\begin{array}{l}\text { Career } \\
\text { advancement }\end{array}$ & $62.5 \%$ & $28.6 \%$ & $2.5 \%$ & $.03^{*}$ \\
\hline Personal growth & $71.9 \%$ & $60.7 \%$ & $57.1 \%$ & .49 \\
\hline Other & $3.1 \%$ & $7.4 \%$ & $0.0 \%$ & .40 \\
\hline
\end{tabular}

* The goal of career advancement was the only goal different at a statistically significant level.

When asked about employment status, $67.6 \%$ of the experimental group indicated they were employed full-time, while just $7.5 \%$ of participants in each of the comparison groups were employed full-time. Although this breakdown was expected, it is shared here to accentuate the work responsibilities and generally complex lives of the post-RN nurses.

\section{Geographical Communities}

The geographical communities of the nurses from the experimental group and the sociology students from comparison group \#2 were distributed. All of the nursing students in comparison group \#1 resided in Sudbury. 


\section{Self-report Data Related to Online Education}

Of the experimental group, $65.8 \%$ reported that they had taken an online course or a course with online components previously, while $85.7 \%$ of comparison group \#1 and $17.2 \%$ of comparison group \#2 reported prior experience with online learning. The high percentage noted for comparison group \#1 may reflect the commitment of Laurentian University's School of Nursing to use online learning strategies in all programs, not just distance programs. Comparison group \#2, whose members were not in nursing, is probably a fair representation of the online learning experience of the entire undergraduate student population at Laurentian.

Table 2 shows the participants' experience with online communication tools as reported before their courses. The absence of an effect was noted for email, but group differences for chat and bulletin board were found to be statistically significant. These differences may be related to the younger participants' greater experience with these communication tools.

Table 2: Participants' Reported Use of Internet Technologies before Online Course

\begin{tabular}{|c|c|c|c|c|}
\hline Tool & $\begin{array}{c}\text { Experimental } \\
(n=34)\end{array}$ & $\begin{array}{c}\text { Comparison } \\
\# 1(n=28)\end{array}$ & $\begin{array}{c}\text { Comparison } \\
\# 2(n=22)\end{array}$ & $p$ \\
\hline Email & $93.8 \%$ & $96.4 \%$ & $100.0 \%$ & .50 \\
\hline Chat & $56.3 \%$ & $85.2 \%$ & $81.0 \%$ & $.03^{*}$ \\
\hline Bulletin Board & $64.5 \%$ & $92.9 \%$ & $33.3 \%$ & $.00^{*}-x+1$ \\
\hline
\end{tabular}

\section{Self-perceptions in Skill Areas of Online Education}

Before starting their courses, study participants were asked to use a Likert scale tool, ranging from 0 to 5 , to rate their perceptions of their competence in four skill areas typically required in university-level online courses: use of the computer; use of the Internet; keyboarding; and university-level writing. For each variable, a one-way ANOVA was conducted, and the only variable to show a statistically significant difference was writing. Further analysis revealed that the experimental group of post-RN nurses reported significantly poorer scores for writing than those in both comparison groups.

In the post-course context, participants in comparison group \#1 were not asked to complete the skill ratings since their course was face-to-face. Although their course had an optional website, with email and a bulletin board, the students rarely used it. Participants in the experimental group and in comparison group \#2 were queried again about their perceptions in the 
four skill areas. Table 3 shows their scores as they rated their skills in the four areas before and after their course.

Table 3: Reported Perceptions of Competence in Skill Areas of Online Learning (Pre and Post Values)

\begin{tabular}{llcccccc}
\hline \multirow{2}{*}{$\begin{array}{l}\text { Area of } \\
\text { perceived } \\
\text { competency }\end{array}$} & Group & \multicolumn{2}{c}{$N$} & \multicolumn{2}{c}{$M$} & \multicolumn{2}{c}{$S D$} \\
\hline Computer & Exe & Post & Pre & Post & Pre & Post \\
& Comp. \#1 & 28 & -- & 3.96 & -- & 1.00 & -- \\
& Comp. \#2 & 21 & 22 & 4.29 & 4.32 & 1.06 & .72 \\
\hline Internet & Experimental & 32 & 34 & 4.00 & 4.03 & .80 & .94 \\
& Comp. \#1 & 28 & -- & 4.18 & -- & .77 & -- \\
& Comp. \#2 & 21 & 22 & 4.24 & 4.45 & 1.00 & .67 \\
\hline Keyboarding & Experimental & 32 & 34 & 4.06 & 4.06 & .88 & 1.13 \\
& Comp. \#1 & 28 & -- & 4.29 & -- & .94 & -- \\
& Comp. \#2 & 21 & 22 & 4.67 & 4.73 & .80 & .77 \\
\hline University- & Experimental & 32 & 34 & 2.69 & 3.24 & 1.35 & 1.02 \\
level writing & Comp. \#1 & 28 & -- & 3.64 & -- & .83 & -- \\
& Comp. \#2 & 21 & 22 & 3.67 & 3.73 & .58 & .55 \\
\hline
\end{tabular}

To examine for change over time-as defined by the beginning and end of the course-within the skill areas, a $2 \times 4 \times 2$, three-way ANOVA was run with Group (experimental group, comparison group \# 2), Scale (computer, Internet, keyboarding, and writing), and Time (pre-test, post-test) as the independent variables. This test, together with some post-hoc analyses, showed a significant post-test increase for the experimental group only, and only in the area of writing. The large difference in perception of writing competence between the two groups at pre-test and the increase between pre-test and post-test for the experimental group are shown in Figure 2. The depressed writing confidence of the older students in the experimental group was dramatically mitigated at post-test, apparently as a function of the online course experience. 


\section{Self-Perceived Writing Competencies}

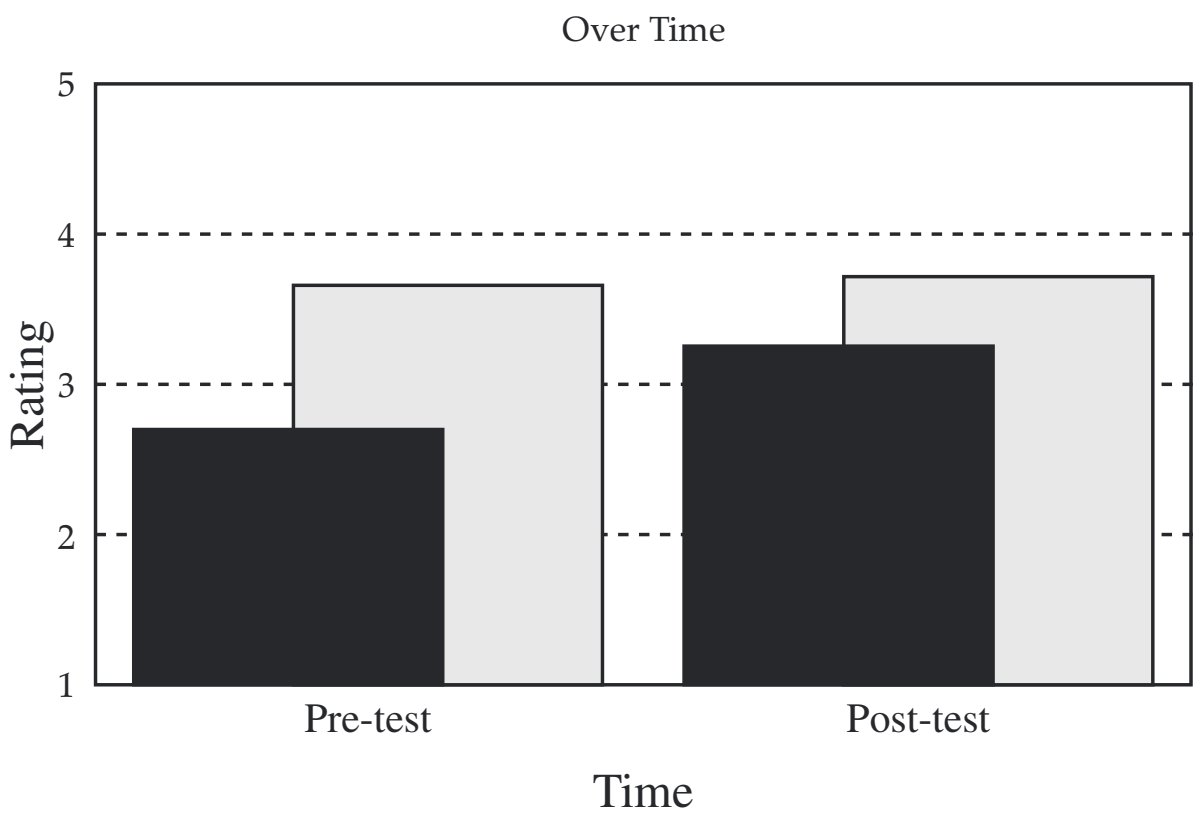

Figure 2:

The interaction effect is due to the large difference in writing ratings at pre-test that was not seen at post-test. The only post-test gain was in writing and only for the experimental group.

\section{Writing Competence}

\section{Critical-thinking Scores Based on Writing Samples}

For each course, a writing sample of each study participant was taken from the same assignment completed near the end of the course. Although the assignments varied in length and topic due to the different content areas, according to the instructors of these courses, each assignment involved critical thinking.

Each sample was scored twice: first by the researcher and then by a rater whose experience was similar to that of the researcher. A four-point criticalthinking rubric for scoring the level of critical thinking in written work (4 being strong and 1 being weak) was used by each scorer.

The scores provided by the second rater were used for analysis because of the possible expectancy effect of the researcher for the participants in the experimental group to do well. Based on these scores, a one-way ANOVA was computed for the writing results for the three groups, which revealed 
a main effect. The post-hoc analysis showed that comparison group \#1 received slightly higher ratings than the experimental group. There were no differences with respect to comparison group \#2, which may be related to the smaller sample size of this group. It would appear that those in comparison group \#1 demonstrated greater proficiency in critical thinking in their writing samples than the members of either the experimental group or comparison group \#2.

The difference between the experimental group and comparison group \#1 is interesting. Some members of the experimental group had not participated in written assignments for some time, and this may have been their first experience of writing at a university level. In comparison group \#1, the students had been exposed to writing at university for more than two years.

\section{Further Scoring of Writing Samples}

Because inter-rater reliability between the two sets of scores (.553) was problematic, the researcher conducted further analysis of the writing samples. First, she had the writing samples scored a third and fourth time by two other raters with backgrounds similar to hers and that of the second rater; next, she analyzed the writing samples using a framework that tracked elements suggested by composition experts to be components of writing competence at a micro level; finally, she conducted a thematic analysis of the samples for different kinds of critical thinking based on Johns (1995).

The inter-rater reliability problem was not addressed through the additional scoring. As with the second rater, the researcher had trained the third and fourth scorers and provided copies of the assignments and the scoring rubric in advance of their rating work. In effect, this inter-rater reliability problem suggests that subjective judgments of written texts by even experienced scorers are sometimes unreliable and readers are advised to be extremely cautious in considering the results of this study.

\section{Analysis of Writing Competence}

As for the writing samples, no statistically significant differences were found among the three groups for spelling, word choice, and sentence length, but there were significant group differences for grammatical errors and vocabulary. Post-tests for grammatical errors revealed that the experimental group made a greater number of grammatical errors, while post-tests for vocabulary showed lower vocabulary scores by the experimental group relative to comparison group \#1 (although the experimental group did score higher than comparison group \#2 for vocabulary complexity). The lower vocabulary scores of comparison group \#2 may have been due to the autobiographical nature of the group's writing assignment. Table 4 displays these results. 
Table 4: Means and Standard Deviations Based on Analyses of Participants' Writing Samples

\begin{tabular}{lllll}
\hline Index & Group & $n$ & $M$ & $S D$ \\
\hline Spelling & Experimental & 32 & .29 & .509 \\
& Comparison \#1 & 18 & .30 & .248 \\
& Comparison \#2 & 8 & .19 & .109 \\
\hline \multirow{2}{*}{ Grammar } & Experimental & 32 & 1.40 & 1.030 \\
& Comparison \#1 & 18 & .67 & .467 \\
& Comparison \#2 & 8 & 1.04 & .481 \\
\hline \multirow{2}{*}{ Word Choice } & Experimental & 32 & .66 & .486 \\
& Comparison \#1 & 18 & .97 & .653 \\
\hline Sentence Length & Comparison \#2 & 8 & .54 & .218 \\
& Experimental & 32 & 3.79 & .828 \\
& Comparison \#1 & 18 & 4.09 & .705 \\
\hline Vocabulary & Comparison \#2 & 8 & 4.07 & .926 \\
\hline & Experimental & 32 & 19.45 & 6.309 \\
& Comparison \#1 & 18 & 24.74 & 3.640 \\
\hline
\end{tabular}

\section{Ways of Thinking in Writing Assignments}

The decision to code thematically for ways of thinking was based on two factors: the noted problems in the scoring of critical thinking and the prevalence of the "ways of knowing" framework (Johns, 1995) in all of the courses and programs offered by the School of Nursing at Laurentian University. Although the students in comparison group \#2 were not nurses, the framework was deemed to be appropriate for this group given the reflective autobiographical nature of the group's writing assignment. The researcher had used Johns's (1995) framework previously in her work with two research teams from Laurentian's School of Nursing and had been the primary author for two peer-reviewed articles based on Johns's work (Carter et al., 2006; Carter \& Rukholm, 2002).

In the study informing this article, as in the previously noted projects, Johns's terms "knowing" and "ways of knowing" were changed to "thinking" and "kinds of thinking." Although the distinctions between knowing and thinking were acknowledged, this modification was appropriate. When 
Johns's categories are broken down into questions, they become a kind of scaffolding for four kinds of thinking: aesthetic, personal, ethical, and empirical. Aesthetic thinking involves challenges to the self, that is, it involves an individual reflecting on what she or he is trying to achieve and the course of action to achieve it. Personal thinking focuses on feelings. Ethical thinking deals with the issue of congruence between an individual's actions and value system. Empirical thinking involves reflecting on how knowledge informs practice.

The researcher began her analysis by reading all of the writing samples twice to gather a general sense of the assignments. Individual assignments were then re-read and discrete ideas were coded in relation to the four kinds of thinking. Where there was ambiguity, sections were re-read until the researcher was confident in her final decision.

The assignment for the experimental group, the post-RN nurses, involved a case study with a family focus. The nurse-writers were asked to demonstrate, from the perspective of a community nurse, critical thinking by responding in narrative form to four questions. Their answers were evaluated on the basis of content and references to evidence-based practice literature. Empirical thinking was demonstrated most frequently by the members of this group; in every sample, the student began with an iteration of what was empirically known. Some students also demonstrated aesthetic thinking, by exploring what they were trying to achieve and why they responded as they did. They tended to demonstrate this kind of thinking when they were reflecting on their role as a care provider. At times, this self-assessment was visible in the words they used; on other occasions, it was more subtle and found in the tone of their writing. Personal thinking was minimally evident.

The assignment completed by comparison group \#1 participants was a critical literature review based on a nursing topic of their choice. Like the post-RN nurses, these nurse-students were asked to prepare an assignment that showed their mastery of English composition and APA writing conventions. Due to the nature of this assignment, the way of thinking demonstrated by the students was almost exclusively empirical. Although the assignment description did not specify that personal ideas or experiences were unacceptable, this perception appeared to be the students' understanding and there was almost no evidence of the other ways of thinking suggested by Johns (1995).

Comparison group \#2 participants were given an autobiographically based assignment in which they were asked to reflect on their adolescence and what they experienced during it that signalled or affected their emerging adulthood. Students who did not wish to prepare an autobiography were welcome to write a biography based on the life of a real or fictional individual. This assignment resulted in many examples of empirical 
thinking, as well as examples of aesthetic and personal thinking and, on a limited number of occasions, ethical thinking. This diversity may have been due not only to the topic but also to the point of view the students were encouraged to assume and that they were asked to connect their observations to the theories they were studying in the course.

As well as displaying more kinds of thinking in general, students in comparison group \#2 displayed greater variety in their kinds of thinking (as Table 5 illustrates), a result that may be related to the general topic and the nature of their assignment. When people write about themselves, they have an "easy-to-access" repository of empirical data: no one can know the empirical events of a person's life better than that person. In this group's assignment, empirical data were complemented by connections that were made to course readings and lecture notes. Reflection on important life events would quite naturally foster thinking that Johns (1995) calls aesthetic and personal. Finally, it seems reasonable to suggest that, when writers reflect on their adolescence, there might be instances of ethical thinking given the turbulence and conflict frequently associated with this life stage.

Table 5: Means and Standard Deviations Based on Ways of Thinking in Writing Samples (based on Johns's [1995] Framework)

\begin{tabular}{llrr}
\hline Way of thinking & Group & $\boldsymbol{M}$ & \multicolumn{1}{c}{$\boldsymbol{S D}$} \\
\hline Empirical & Experimental & 22.91 & 8.058 \\
& Comparison \#1 & 36.00 & 6.417 \\
& Comparison \#2 & 42.50 & 1.512 \\
\hline \multirow{2}{*}{ Personal } & Experimental & .56 & 1.190 \\
& Comparison \#1 & .00 & .000 \\
\hline \multirow{2}{*}{ Aesthetic } & Comparison \#2 & 14.38 & 6.610 \\
& Experimental & 6.47 & 3.951 \\
& Comparison \#1 & .61 & 1.037 \\
\hline \multirow{2}{*}{ Ethical } & Comparison \#2 & 18.25 & 5.092 \\
& Experimental & .44 & .716 \\
& Comparison \#1 & .00 & .000 \\
& Comparison \#2 & 3.63 & 1.847 \\
\hline
\end{tabular}

Extrapolating, it may be that coding for different kinds of thinking provides support for the idea that written assignments can elicit different kinds of thinking. Therefore, if fostering particular kinds of thinking is a valued educational goal, specific attention to assignment design is suggested. 
Additionally, assuming that it is preferable for nurse-learners to practice different ways of thinking in the safety of a learning setting rather than in today's fast-paced clinical setting, it may be especially important for instructors to take additional care in the development of written assignments.

\section{DISCUSSION}

It is essential not to over generalize any of the study findings because of its sample size and other limitations. Nonetheless, a number of findings merit further consideration and investigation. In terms of the first hypothesis to be assessed by the study - that online courses that include asynchronous reflective-writing activities increase learners' perception of their competence as a writer-based on the self-report data, it appears that this may be the case. Although improvement was reported by all participants, the most dramatic gain occurring at a statistically significant level involved the post-RN nurses. Given this outcome, researchers may wish to continue to study the role that online courses play in mitigating the anxieties of adult learners about writing and increasing their confidence as university-level writers.

The results of the study suggested that the active participation of the learners and their engagement with each other and their instructors were the primary influences on their writing confidence. For those in the experimental group, communicating through writing, posting different kinds of reflective writing in a common learning space, reading others' postings, participating in a learning culture in which students faced similar life challenges, and receiving support from caring instructors may have comprised the "right climate" for facilitating an increase in their confidence as writers.

The finding that the post-RN group did not write as competently as their younger peers is possibly due to the group's composition. As a group, these post-RN nurses had varying levels of academic writing experience, with some being exposed to university-level writing for the first time and those near the end of the post-RN program having already taken several courses requiring academic writing. Thus, targeted instruction in writing in the discipline of nursing is recommended for students new to the post-RN program.

The study's second hypothesis-that online courses that include asynchronous reflective-writing activities facilitate the demonstration of criticalthinking skills through writing - could not be supported or rejected. Despite the best efforts of the researcher and three other writing experts from Laurentian University to assess students' writing samples for evidence of critical thinking via holistic scoring (Facione \& Facione, 1992), no conclusions could be drawn because of inter-rater reliability problems.

Although there are likely many reasons for the problems encountered with the scoring activity, two stand out: the first pertains to the challenges 
of measuring critical-thinking skill; the second pertains to the assessment of writing. Some educators regard the context-based test as the most appropriate measure of critical-thinking skill (Norris \& Ennis, 1989; Pascarella \& Terenzini, 1991; Pendarvis, 1996). Unfortunately, a confounding variable with this kind of testing is that the test taker's score is likely to be affected by prior knowledge of the discipline. In nursing education, the only way to validate that a nurse-learner who takes a context-based test can apply critical thinking in practice is to follow that nurse in the clinical setting; clearly, this is an expensive and impractical way of validating the critical thinking of nurses. If, however, researchers (including this researcher/writer) maintain that writing has some "inherent ... advantages over speech when engaged in critical discourse and reflection" and that writing can be both "a process and product of rigorous critical thinking" (Garrison \& Anderson, 2003, p. 26), it is appropriate to continue to search for ways to assess for evidence of critical thinking in writing. However, as experienced in the study informing this article, this is no easy undertaking.

Similarly, the scoring of writing has historically challenged writing instructors and those who teach in content areas where demonstration of acquired knowledge and skills relies heavily on writing (Barnet, Berman, Burto, Cain, \& Stubbs, 2000; Kirszner \& Mandell, 2001; Schoonen, 2005; Troyka, 2004). The hypothesis of a possible connection between online reflective writing and critical-thinking skill has, therefore, brought together three extremely complex areas: evaluation, critical-thinking skills, and writing.

Two additional outcomes resulted from the researcher's "less than successful" scoring experience. The first was her renewed respect for the intricacies and complexities of assessment of critical-thinking skill as demonstrated in writing. As Hara, Bonk, and Angeli (2000) pointed out, "There is a pressing need to consider the dynamics of online discussion and how it facilitates students' cognitive and metacognitive development" (p. 125); however, measurement of critical-thinking skill is a complex task since there is no "generally accepted model to evaluate critical thinking" (McLean, 2005, p. 2). Hence, while the researcher would recommend that only psychometrically sound instruments be used in any research work related to critical thinking, when the thinking is embedded in writing, there will always be some element of subjectivity.

The second outcome was the researcher's decision to study the participants' writing in two additional ways-for general writing competence, by tracking writing errors, and for evidence of ways of thinking, based on Johns' (1995) framework. Although the post-RN nurses' increased writing confidence suggests a confidence-building effect related to their online experience, there is still work to be done to enhance their actual writing and bring it in line with that of younger university students. 
From the researcher's perspective, these findings were not difficult to understand: all of the undergraduate nursing students had experienced at least 2.5 years of university before the study. By contrast, for some of the post-RN nurses, this was their first university course. Additionally, unlike the majority of post-RN learners, the majority of comparison group \#1 participants had not encountered major interruptions in their academic-writing experiences, having recently progressed from high school to university. Based on the weaknesses identified in the written work of the post-RN nurses, universities are encouraged to develop special supports for older adult learners taking courses where writing is central to success. Such resources, however, must fit the busy schedules of these learners; ideally, they should be integrated as much as possible into the actual course experience.

Although the coding work based on Johns (1995) was completed on a small sample, a connection was suggested between kinds of thinking and assignment design. Thus, when cultivation of different kinds of thinking is an identified learning objective, activities and assignments require specific developmental attention. In online courses where written communication is the primary learning tool, course designers and content experts need to build on the strengths and limitations of written assignments and respect the uniqueness of the online writing experience.

\section{IMPLICATIONS AND CONCLUSIONS}

The study that informs this article contributes to the fields of online education and continuing education when the learning framework is constructivist based. Most importantly, the results of the study encourage educators, researchers, and administrators to continue to examine the relationship between participatory online courses and learners' experiences of writing. As more is understood about the writing experiences of online learners, then more appropriate choices can be made in the design of online courses when the demonstration of critical thinking, through writing, writing confidence, and writing competence, is a course goal. Although the study revealed a discrepancy between the writing competence of older and younger nurselearners, the responsibility for addressing this shortcoming does not necessarily reside with the online and/or continuing education unit. Instead, adult educators are encouraged to work collaboratively with content experts to effectively address this situation. A further recommendation, then, based on the results of the study is that interdisciplinary teams are appropriate if online learning continues to be largely text based.

More work is also required in the instructional-design field. Designers, content experts, and teachers must move toward an enhanced 
understanding of how to plan for knowledge building in non-prescriptive ways, work that includes exploring learning activities and assignments that can be completed and presented online. In nursing education, this work may also include developing and piloting online assignments that draw on the lived experiences of registered nurses and follow the principles of case-based learning. Another area of potential study is how different kinds of online assignments foster different kinds of thinking and writing. Such work would influence the instructional-design models that have emerged over the last decade and focus on online education and constructivism.

Taken together, the study's findings and the recommendations based on them are part of an expanding literature that informs and shapes the art and science of online education. Clearly, online education is now a cornerstone of post-secondary education, and writing continues to be one of its principal learning methods. Thus, it is essential that educators learn as much as they can about the powerful combination of critical thinking and writing in the online educational environment.

\section{REFERENCES}

Ally, M. (2004). Foundations of educational theory for online learning. In Terry Anderson \& Fathi Elloumi (Eds.), Theory and practice of online learning (pp. 3-31). Athabasca, AB: Athabasca University. Retrieved February 5, 2005, from http://cde.athabascau.ca/online_book/ch1.html.

Anderson, T. (2003). Modes of interaction in distance education: Recent developments and research questions. In M. Moore (Ed.), Handbook of distance education (pp. 129-145). Mahwah, NJ: Erlbaum.

Barnet, S., Berman, M., Burto, W., Cain, W. E., \& Stubbs, M. (2000). Literature for composition: Essays, fiction, poetry, and drama. New York: Longman.

Brown, H. N., \& Sorrell, J. M. (1993). Use of clinical journals to enhance critical thinking. Nurse Educator, 18(5), 16-19.

Burrows, D. E. (1995). The nurse teacher's role in the promotion of reflective practice. Nurse Education Today, 15, 346-350.

Carter, L., \& Rukholm, E. (2002). On-line scholarly discourse: Lessons learned for continuing and nurse educators. Canadian Journal of University Continuing Education, 28(2), 31-48.

Carter, L., Rukholm, E., Mossey, S., Viverais-Dresler, G., Bakker, D., \& Sheehan, C. (2006). Critical thinking in the online nursing education setting: Raising the bar. Canadian Journal of University Continuing Education, 32(1), 27-46. 
Council of Ontario Universities Highlights. (2000, May). Funding for collaborative nursing programs set out. Retrieved July 15, 2002, from http://www. cou.on.ca?content/objects/CH_May2000.pdf

Daroszewski, E. B., Kinser, A. G., \& Lloyd, S. L. (2004). Online, directed journaling in community health advanced practice nursing clinical education. Journal of Nursing Education, 43(4), 175-180.

Facione, P. A ., \& Facione, N. C. (1992). Holistic critical thinking scoring rubric. Millbrae, CA: California Academic Press.

Facione, P.A., Facione, N.C., \& Giancarlo, C. (2001). California Critical Thinking Disposition Inventory Manual. Millbrae, CA: California Academic Press.

Garrison, D. R., \& Anderson, T. (2003). E-learning in the 21st century: A framework for research and practice. London: Routledge.

Gibson, S., \& Rose, M. (1986). Managing computer resistance. Personal Computing, 4, 201-204.

Hara, N., Bonk, C. J., \& Angeli, C. (2000). Content analysis of online discussion in an applied educational psychology course. Instructional Science, $28,115-152$.

Ibarreta, G. I., \& McLeod, L. (2004). Thinking aloud on paper: An experience in journal writing. Journal of Nursing Education, 43(3), 134-137.

Johns, C. (1995). Framing learning though reflection within Carper's fundamental ways of knowing in nursing. Advanced Nursing Practice, 22, 226-234.

Jonassen, D. H. (1991). Evaluating constructivistic learning. Educational Technology, 28(11), 13-16.

Kennison, M. M., \& Misselwitz, S. (2002). Evaluating reflective writing for appropriateness, fairness, and consistency. Nursing Education Perspectives, 23(5), 238-242.

Kessler, P., \& Lund, C. (2004). Reflective journaling: Developing on-line journals for distance education. Nurse Educator 29(1), 20-24.

Kirszner, L. G., \& Mandell, S. R. (2001). Instructor's guide to accompany literature: Reading, reacting, writing. Fort Worth, TX: Harcourt College Publishers.

McLean, C. (2005). Evaluating critical thinking skills: Two conceptualizations. Journal of Distance Education, 20(2), 1-20.

McVicar, A. (2003). Workplace stress in nursing: A literature review. Journal of Advanced Nursing, 44(6), 633-642. 
Mujtaba, B. G., \& Preziosi, R. C. (2006). Adult education in academia: Recruiting and retaining extraordinary facilitators of learning. Greenwich, CT: Information Age Publishing.

Murphy, K. L., \& Cifuentes, L. (2001). Using Web tools, collaborating, and learning online. Distance Education, 22(2), 285-305.

Norris, S., \& Ennis, R. (1989). Evaluation of critical thinking. Pacific Grove, CA: Midwest Publications.

Pascarella, E. T., \& Terenzini, P. T. (1991). How college affects students: Findings and insights from twenty years of research. San Francisco: Jossey-Bass.

Pendarvis, F. (1996). Critical thinking assessment: Measuring a moving target. Rock Hill, SC: The South Carolina Higher Education Assessment Network.

Schoonen, R. (2005). Generalizability of writing scores: An application of structural equation modeling. Language Testing, 22(1), 1-30.

Sedlak.A. (1997). Critical thinking of beginning baccalaureate nursing students during the first clinical nursing course. Journal of Nursing Education, 36, 11-18.

Seels, B. (1989). The instructional design movement in educational technology. Educational Technology, 29(5), 11-15.

Smith, B., \& Johnston, Y. (2002). Using structured clinical preparation to stimulate reflection and foster critical thinking. Journal of Nursing Education, 41(4), 182-189.

Stordeur, S., D’Hoore, W., \& Vandenberghe, C. (2001). Leadership, organizational stress, and emotional exhaustion among hospital nursing staff. Journal of Advanced Nursing, 35(4), 533-540.

Troyka, L. Q. (2004). Quick access: Reference for writers. Scarborough, ON: Prentice-Hall Canada.

Wilson, B. G., \& Cole, P. (1991). A review of cognitive teaching models. Educational Technology Research and Development, 39(4), 47-64.

Wilson, B.G. (1997). The postmodern paradigm. In C.R. Dills \& A. A. Romiszowski (Eds.), Instructional development paradigms. Englewood Cliffs, NJ: Educational Technology Educational Technology Publications. 


\section{BIOGRAPHY}

A faculty member in Laurentian University's School of Nursing, Lorraine Carter has extensive national-level experience as an instructional designer, project manager, and researcher in online and distance education applications. Her PhD thesis in Educational Studies examined the critical thinking and writing experiences of post-RNs taking online courses.

Membre du corps professoral de l'École des Sciences infirmières à l'Université Laurentienne, Lorraine Carter a une grande expérience au niveau national comme conceptrice de matériel pédagogique, comme gérante de projet, et comme chercheuse auprès des applications en ligne et de l'éducation à distance. Dans sa thèse de doctorat en Études en matière d'éducation, elle examina les expériences de pensée critique et d'écrire des infirmières autorisées suivant des cours en ligne. 